\title{
Apparent Triphasic T-Wave
}

\section{Steven Mickelsen, Emir Festic}

From the Departments of Internal Medicine and Critical Care Medicine Mayo Clinic Florida, USA

Festic.Emir@mayo.edu

Tel.: + 904-956-3331

Fax: + 904-956-3332

Received: 2 October 2011

Accepted: 16 November 2011

Copyright (C) 2011 by Academy of Sciences and Arts of Bosnia and Herzegovina. Email for permission to publish: amabih@ anubih.ba

An apparent "triphasic" $\mathrm{t}$-wave was seen in a 59-year-old man upon admission to the intensive care unit. The physician was called to identify the change in rhythm (Panel A). The exam was unremarkable and the patient remained hemodynamically stable. Changing the lead configuration on the monitor revealed bigeminy (Panel B). The wide complex beats most likely represented a triggered ventricular phenomena. However, atrial bigeminy with rate dependent bundle branch could not be ruled out. A 12-lead EKG performed later suggested the diagnosis of ventricular bigeminy (Panel C). This case emphasizes the utility of using multiple leads to differentiate immediately artifacts and distortions commonly seen on rhythm monitors. Performance of 12-lead ECG, a "gold standard" for noninvasive diagnosis of rhythm disturbances, may sometimes be delayed. Changing the leads is a simpler, quicker action and therefore should be performed first. In our case, inspection of other leads was diagnostic and allowed for 12-lead ECG to be performed nonurgently. The unusual appearance of this rhythm may be misleading at first glance. However, interpreting the wide QRS as a second of three t-waves would be very difficult to explain. There are
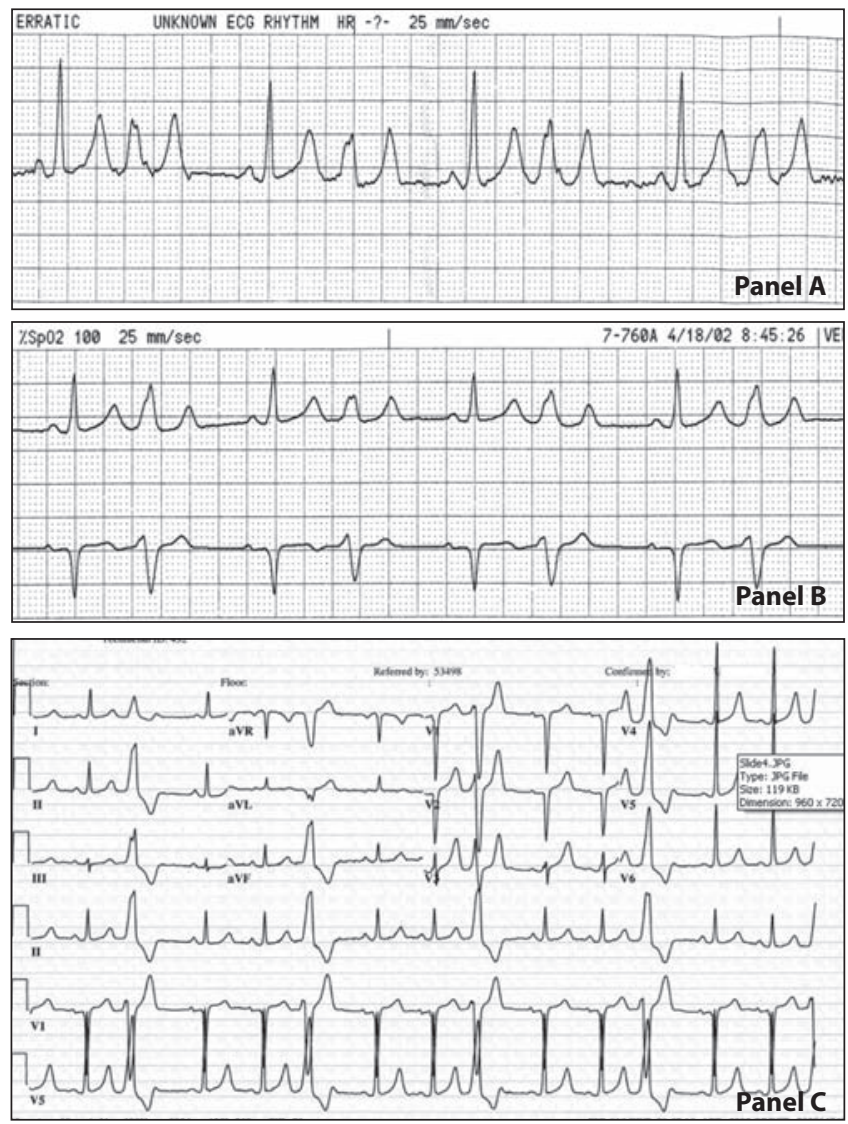

a number of repolarization abnormalities that can produce notched, bifid, and/or prominent u-waves but a "triphasic" t-wave with this morphology does not fit any known pattern (1). Ventricular bigeminy is commonly associated with hypokalemia, medications such as digoxin and underlying ischemia. The compensatory pause after each VPC tends to perpetuate conditions favoring more bigeminy (2). No underlying electrolyte abnormalities or culprit medications were identified and the arrhythmia resolved spontaneously with no clinical sequela.

Conflict of interest: The authors declare that they have no conflict of interest. This study was not sponsored by any external organisation.

\section{References}

1. Watanabe Y, Toda H, Nishimura M. Clinical electrocardiographic studies of bifid T waves. Br Heart J. 1984;52(2):207-14.

2. Wang K, Asinger RW, Marriott HJ. Bigeminal rhythms, common and uncommon mechanisms. J Electrocardiol. 2007;40(2):135-8. 